\title{
Epidemiology of osteoporotic fracture in Kazakhstan and development of a country specific FRAX model
}

\author{
S. Issayeva ${ }^{1} \cdot$ O. Lesnyak ${ }^{2} \cdot$ A. Zakroyeva ${ }^{3} \cdot$ B. Issayeva ${ }^{1} \cdot$ D. Dilmanova ${ }^{1} \cdot$ H. Johansson ${ }^{4} \cdot$ E. Liu $^{4} \cdot$ M. Lorentzon ${ }^{4,5}$. $^{6}$ \\ N.C. Harvey ${ }^{6} \cdot$ E. McCloskey ${ }^{7}$ - J.A. Kanis ${ }^{4,7}$
}

Received: 23 October 2019 / Accepted: 15 January 2020 / Published online: 27 February 2020

(C) The Author(s) 2020

\begin{abstract}
Summary Retrospective and prospective population-based survey in a region of the Republic of Kazakhstan determined the incidence of fractures at the hip, proximal humerus and distal forearm. The hip fracture rates were used to create a FRAX® model to enhance fracture risk assessment in Kazakhstan.

Objective This paper describes the epidemiology of osteoporotic fractures in the Republic of Kazakhstan that was used to develop a country specific FRAX® tool for fracture prediction.

Methods We carried out a retrospective population-based survey in Taldykorgan in the Republic of Kazakhstan representing approximately $1 \%$ of the country's population. Hip, forearm and humerus fractures were identified retrospectively in 2015 and 2016 from hospital registers and the trauma centre. Hip fractures were prospectively identified in 2017 from the same sources and additionally from primary care data. Age- and sex-specific incidence of hip fracture and national mortality rates were incorporated into a FRAX model for Kazakhstan. Fracture probabilities were compared with those from neighbouring countries having FRAX models.

Results The difference in hip fracture incidence between the retrospective and prospective survey indicated that approximately $25 \%$ of hip fracture cases did not come to hospital attention. The incidence of hip fracture applied nationally suggested that the estimated number of hip fractures nationwide in persons over the age of 50 years for 2015 was 11,690 and is predicted to increase by $140 \%$ to 28,000 in 2050. Hip fracture incidence was a good predictor of forearm and humeral fractures in men but not in women.

Conclusion The FRAX model should enhance accuracy of determining fracture probability among the Kazakh population and help guide decisions about treatment.
\end{abstract}

Keywords FRAX $\cdot$ Fracture probability $\cdot$ Epidemiology $\cdot$ Hip fracture $\cdot$ Forearm fracture $\cdot$ Humerus fracture $\cdot$ Kazakhstan

J.A. Kanis

w.j.pontefract@sheffield.ac.uk

1 Asfendiyarov National Medical University, 94, Tole Bi Street, Almaty, Kazakhstan 050000

2 Mechnikov North West State Medical University, 41, Kirochnaya Street, 191015 St. Petersburg, Russia

3 Ural State Medical University, 3, Repina Street, 620028 Yekaterinburg, Russia

4 Mary McKillop Health Institute, Australian Catholic University, Melbourne, Australia

5 Institute of Medicine, University of Gothenburg, Gothenburg, Sweden

6 MRC Lifecourse Epidemiology Unit, University of Southampton, Southampton, UK

7 Centre for Metabolic Bone Diseases, University of Sheffield, Sheffield, UK

\section{Introduction}

Osteoporosis is a common, chronic and costly condition; its only clinical consequence is fracture. In Europe, the annual cost of fractures associated with osteoporosis exceeded $€ 37$ billion in 2010 [1], and disability due to osteoporosis was greater than that caused by any single cancer, with the exception of lung cancer and was comparable or greater than that lost to a variety of chronic noncommunicable diseases, such as rheumatoid arthritis, asthma and high blood pressure related to heart disease [2]. Fortunately, a wide variety of treatments is available that favourably affect bone mass and thereby decrease the risk of fractures associated with osteoporosis [3]. The use of such interventions by health care practitioners is assisted by instruments that assess patients' fracture risk to optimize clinical decisions about prevention and treatment. The most widely used web-based tool FRAX® (https:// 
www.sheffield.ac.uk/FRAX/) meets these requirements and computes the 10-year probability of fragility fractures based on several common clinical risk factors and optionally a DXA scan result [4, 5]. FRAX models are available for 66 countries in 2020 covering more than $80 \%$ of the world population at risk [6], and have been incorporated into more than 100 guidelines worldwide [7].

The availability of FRAX has stimulated studies that can be used for the generation of new FRAX models. Specific examples include Brazil, Mexico and Turkey [8]. The present study is a component part of the Multicenter Multinational population-based Study in Eurasian Countries (EVA study or ЭBA, in Russian). The broad aim of the study was to provide epidemiological information on fracture risk so that FRAX models could be created for Russia [9], Armenia [10], Belarus [11], Moldova [12], Kazakhstan and Uzbekistan. The present report describes the epidemiology of fractures at the hip, forearm and humerus in Kazakhstan and the generation of a country specific FRAX model.

\section{Methods}

The Republic of Kazakhstan is the world's largest landlocked country and the ninth largest in the world, with an area of 2,724,900 $\mathrm{km}^{2}$. Kazakhstan shares borders with Russia, China, Kyrgyzstan, Uzbekistan, Turkmenistan, and the Caspian Sea. In 2015 the population of Kazakhstan was 17.75 million and rose to 18.20 million in 2017 [13].

For the present study, Taldykorgan (Taldıqorğan), the administrative centre of Almaty Region of Kazakhstan, was chosen as the catchment area. Taldykorgan was selected because of its long distance from other major cities of the Republic and the availability of highly specialized orthopaedic care for all Taldykorgan residents. This minimized the possibility of residents seeking medical care for their fracture in neighbouring cities. Each individual in Kazakhstan has a unique digital code which permits the number of residents to be determined by region, age and sex, the precise number of inhabitants counting in any period of time [14]. The total catchment population of the regions was 165,296 representing $0.9 \%$ of the total population. The age, sex and ethnic distribution were very similar to that of the whole country. The ethnic distribution was Kazakhs (66.5\%), Russian (20.6\%) and other ethnicities $(12.9 \%)$ [14].

The study was organized in two phases. The first was a retrospective survey from 1 January 2015 to 31 December 2016 which captured data on data on fractures at the hip (ICD-10 codes S72.0, S72.1, S72.2), distal forearm (S52.5, S52.6) and proximal humerus (S 42.2). The second phase was a prospective survey from 1 March 2017 to 28 February 2018 that acquired data on hip fracture alone.
In both phases, the medical records of all fractures in men and women aged 40 years or older were retrieved from the inpatient electronic health register (EHR) of the three hospitals in the area, the outpatient register of the City Trauma centre. In addition, refusals of hospitalization (formal documents) were examined from all the hospitals of the city. Only fractures validated by radiographs were included. To avoid double counting, further admissions for the same fracture site in the observation time were excluded. In some documents, fracture ICD-10 code was not specified. In such cases, radiographs were retrieved and fractures, if verified, were included in the database. Permanent residence in the region was a criterion for inclusion. All hip fracture cases were included irrespective of high or low energy trauma. We excluded pathological fractures attributable to cancer with metastases or to multiple myeloma.

The prospective study identified new cases of hip fractures using the same methodology as in the retrospective survey. In addition, data were gathered from the records of the emergency call centre, from the records of home visits to patients by orthopaedic doctors from the outpatient polyclinic, the records and outpatient electronic health records of all (32) primary care doctors in the city and two private primary health care centres to find additional non-hospitalized patients. These patients were examined at home, and the hip fracture was verified clinically, and where possible, by radiography.

Yearly incidence rates for fractures of the distal forearm and proximal humerus were estimated from the number of men and women in 5- or 10-year age intervals with at least one index fracture in 2015 and 2016 divided by the age- and sex-specific population at risk. In the case of hip fracture, the prospective study identified more men and women than the retrospective surveys of 2015 and 2016. For example, 65 hip fracture cases were identified in women in 2015 and 65 in 2016. In contrast, an additional 19 fractures were identified in 2017 (i.e. a total of 84 hip fractures). We assumed that a similar number of fractures (19) had been missed in 2015 and 2016 and uplifted the incidence rates in these years by $29 \%$ $((65+19) / 65)$. In the case of men, the incidence was upward revised by $8 \%$.

The adjusted age and sex-specific incidence in 2015-2017 was applied to the Kazakh population in 2015 to estimate the number of hip fractures nationwide. Additionally, future projections were estimated up to 2050 assuming that the age- and sex-specific incidence remained stable. Population demography was taken from the United Nations using the medium variant for fertility [15].

The adjusted data on hip fracture were used to construct the FRAX model. For other major osteoporotic fractures (clinical spine, forearm and humeral fractures), it was assumed that the age- and sex-specific ratios of these fractures to hip fracture, risk found in Sweden were comparable to those in Kazakhstan. This assumption has been used for many of the 
FRAX models with incomplete epidemiological information. Available information suggests that the age- and sex-stratified pattern of fracture is very similar in the Western world, Australia and Eastern Europe [12, 16-18]. In order to test this further, we compared the incidence of a forearm or humeral fracture observed in Kazakhstan with the incidence that would be predicted from the pattern of incidence in Malmo applied to the incidence of hip fracture in Kazakhstan. This assumes that the age- and sex-specific pattern of incidence of proximal humerus and forearm fracture (i.e. other major fractures, OMF) and the adjusted hip fracture (HF) in Kazakhstan are similar to that seen in Malmo [16]. Thus, for each age and sex,

$\frac{\mathrm{HF}_{\text {Kazakhstan }}}{\mathrm{HF}_{\text {Malmo }}}=\frac{\mathrm{OMF}_{\text {Kazakhstan }}}{\mathrm{OMF}_{\text {Malmo }}}$

therefore,

$\mathrm{OMF}_{\text {Kazakhstan }}=\frac{\mathrm{HF}_{\text {Kazakhstan }} \times \mathrm{OMF}_{\text {Malmo }}}{\mathrm{HF}_{\text {Malmo }}}$

From this, the incidence of a forearm or humerus fracture, estimated using the Malmo ratios, was compared with the empirical data from Kazakhstan from the ages of 50-90 years.

The development and validation of FRAX have been extensively described $[4,5]$. The risk factors used were based on a systematic set of meta-analyses of population-based cohorts worldwide and validated in independent cohorts with over 1 million patient-years of follow-up. The construct of the FRAX model for Kazakhstan retained the beta coefficients of the risk factors in the original FRAX model with the incidence rates of hip fracture and mortality rates for Kazakhstan. National mortality rates used data from the World Health Organization for 2015 [19]. Ten-year fracture probabilities were compared to those of neighbouring countries where a FRAX model was available (China and Russia).

In order to compare Kazakh hip fracture probabilities with those of other regions of the world, the remaining lifetime probability of hip fracture from the age of 50 years was calculated for men and women, as described previously [20]. In the present analysis, values for Kazakhstan were compared with those of China (with and without inclusion of Hong Kong), Canada, Denmark, Finland, France, Hungary, Mexico, Moldova, Poland, Portugal, Russia, Spain, Sweden, Turkey, Ukraine, the UK and the USA.

\section{Results}

A total of 1058 fractures were identified in individuals aged 40 years or more. These comprised 348 hip fractures (2015, 2016 and 2017), 174 humerus and 536 distal forearm fractures (2015 and 2016).

\section{Hip fracture}

A total of 134 hip fractures were identified in men and 214 in women (female/male ratio 1.6). Below the age of 70 years, hip fractures were more common in men than in women (female/ male ratio 0.8 ) but thereafter were more frequent in women (female/male ratio 3.1). The incidence of hip fracture increased with age in men and women, though more markedly in women (Table 1). Of the 348 cases of hip fractures, 82 cases formally (24\%) refused hospital admission (27 men and 55 women). The cases that declined admission increased in frequency with age. Of the 266 patients admitted to the hospital, $200(75 \%)$ underwent surgery. In total $43 \%$ of hip fracture cases were either untreated or managed conservatively.

Table 1 Population of the catchment area, number of hip fractures and annual incidence of hip fractures (rate/100,000) in men and in women from Taldykorgan, Kazakhstan by age for 2015, 2016 and 2017 combined

\begin{tabular}{|c|c|c|c|c|}
\hline Age (years) & Population & Fractures $^{\mathrm{a}}$ & $\begin{array}{l}\text { Incidence/ } \\
100,000^{\mathrm{b}}\end{array}$ & $95 \% \mathrm{CI}$ \\
\hline \multicolumn{5}{|l|}{ Men } \\
\hline $40-44$ & 15,668 & 10 & 67 & $31-117$ \\
\hline $45-49$ & 14,234 & 9 & 68 & 29-120 \\
\hline $50-54$ & 13,691 & 10 & 77 & $35-134$ \\
\hline $55-59$ & 11,371 & 18 & 167 & $101-261$ \\
\hline $60-64$ & 8377 & 18 & 225 & $127-353$ \\
\hline $65-69$ & 6387 & 23 & 378 & $241-562$ \\
\hline $70-74$ & 3279 & 8 & 254 & $105-481$ \\
\hline $75-79$ & 2665 & 13 & 527 & $287-884$ \\
\hline $80-84$ & 1323 & 10 & 780 & $362-1390$ \\
\hline $85-89$ & 593 & 12 & 2078 & $1046-3605$ \\
\hline $90-94$ & 211 & 3 & 1536 & $289-4156$ \\
\hline $95+$ & 150 & 0 & - & - \\
\hline $40+$ & 77,949 & 134 & 181 & $152-213$ \\
\hline \multicolumn{5}{|l|}{ Women } \\
\hline $40-44$ & 19,142 & 5 & 31 & $8-61$ \\
\hline $45-49$ & 17,874 & 4 & 271 & $6-57$ \\
\hline $50-54$ & 17,099 & 6 & 42 & $17-84$ \\
\hline $55-59$ & 15,231 & 14 & 109 & $60-176$ \\
\hline $60-64$ & 11,984 & 16 & 158 & 89-247 \\
\hline $65-69$ & 10,058 & 25 & 292 & $193-418$ \\
\hline $70-74$ & 5169 & 21 & 502 & $313-736$ \\
\hline $75-79$ & 5665 & 44 & 925 & $692-1212$ \\
\hline $80-84$ & 2833 & 38 & 1515 & 1096-2042 \\
\hline $85-89$ & 1360 & 31 & 2663 & $1867-3684$ \\
\hline $90-94$ & 357 & 10 & 3207 & $1537-5514$ \\
\hline $95+$ & 108 & 0 & - & - \\
\hline $40+$ & 106,880 & 214 & 236 & $207-266$ \\
\hline
\end{tabular}

${ }^{\mathrm{a}}$ Unadjusted numbers

${ }^{\mathrm{b}}$ Includes adjusted incidence for 2015 and 2016 


\section{Forearm and humeral fractures}

Fractures at the distal forearm were more frequent in women than in men (female/male ratio $=4.3$ ). There was no clear agedependent trend of incidence in women or men (Table 2).

The annual incidence of proximal humerus fractures was lower in men than in women (female/male ratio $=2.6$ ). Humeral fractures were less common than forearm fractures, and in women, increased with age.

\section{Fracture projections}

Assuming that the fracture rates in Taldykorgan was representative for the whole country, and based on the UN estimates of Kazakh population for 2015 , we estimated that the annual number of hip fractures in men and women age 50 years and older in Kazakhstan in 2015 was 11,690, comprising 3815 in men and 7875 fractures in women. The number of hip fractures is expected to increase progressively by calendar year with an increase of $140 \%$ by 2050 (Table 3). The increase in hip fracture numbers is particularly great in women $(153 \%$ in women and $112 \%$ in men) due to the high age dependency of hip fracture incidence.

\section{Fracture probability}

In men, the incidence of forearm and humeral fractures was very similar to that predicted from the epidemiology of fracture in Malmo (Table 4). In women, however, the observed fracture rates exceeded those predicted from the Malmo ratios,
Table 3 Estimated total number of hip fractures (ICD-10 codes S72.0, S72.1 and S72.2) in men and in women age 50 years and older in 2015 projected up to 2050 in Kazakhstan

\begin{tabular}{llllll}
\hline & 2015 & 2020 & 2030 & 2040 & 2050 \\
\hline Men & 3815 & 4298 & 5234 & 6645 & 8110 \\
Women & 7875 & 8653 & 11,293 & 15,837 & 19,938 \\
Total & 11,690 & 12,951 & 16,527 & 22,482 & 28,048 \\
Increase (\%) & - & 11 & 41 & 92 & 140 \\
\hline
\end{tabular}

in some cases significantly so (Table 4). Because of the discordance in the findings between men and women, the FRAX model was based on the data on hip fracture, and the assumed incidence of the other major osteoporotic fractures was determined from the Malmo ratios.

The 10-year probability of major osteoporotic fracture and hip fracture in Kazakhstan and neighbouring countries is shown in Fig. 1 in women with a prior fracture by age. Ten-year probabilities were consistently higher than in the neighbouring country of China. In the case of Russia, 10-year probabilities of a major fracture were similar to those of Kazakhstan, but for hip fracture, the probabilities in Russia were substantially lower than those in Kazakhstan.

Lifetime probabilities for hip fracture are shown in Table 5. As it was the case for 10-year probabilities, lifetime probability of hip fracture was higher than that of Russians or Chinese but substantially lower than rates in Western Europe and North America.
Table 2 Number and annual incidence of forearm and humeral fractures $($ rate $/ 100,000)$ in men and women in Taldykorgan, Kazakhstan by age for 2015 and 2016 combined

\begin{tabular}{|c|c|c|c|c|c|c|}
\hline \multirow[b]{2}{*}{ Age (years) } & \multicolumn{3}{|l|}{ Forearm } & \multicolumn{3}{|l|}{ Humerus } \\
\hline & Fractures & Incidence & $95 \% \mathrm{CI}$ & Fractures & Incidence & $95 \% \mathrm{CI}$ \\
\hline \multicolumn{7}{|l|}{ Men } \\
\hline $40-49$ & 38 & 192 & $136-264$ & 13 & 66 & $35-113$ \\
\hline $50-59$ & 38 & 229 & $162-315$ & 18 & 109 & $64-172$ \\
\hline $60-69$ & 20 & 206 & $126-318$ & 15 & 154 & $86-255$ \\
\hline $70-79$ & 3 & 78 & $16-226$ & 2 & 52 & $6-187$ \\
\hline $80-89$ & 2 & 1658 & $20-598$ & 0 & - & - \\
\hline $90+$ & 0 & & & 1 & 424 & $8-2364$ \\
\hline $40+$ & 101 & 197 & $160-239$ & 49 & 95 & $71-126$ \\
\hline \multicolumn{7}{|l|}{ Women } \\
\hline $40-49$ & 90 & 366 & $294-450$ & 14 & 57 & $31-96$ \\
\hline $50-59$ & 172 & 8046 & 689-934 & 35 & 164 & $114-228$ \\
\hline $60-69$ & 97 & 6736 & $546-821$ & 39 & 271 & $192-370$ \\
\hline $70-79$ & 53 & 743 & 556-971 & 21 & 294 & $182-450$ \\
\hline $80-89$ & 20 & 748 & $457-1156$ & 16 & 599 & $342-972$ \\
\hline $90+$ & 3 & 952 & $196-2785$ & 0 & - & - \\
\hline $40+$ & 435 & 617 & $560-678$ & 125 & 177 & $148-211$ \\
\hline
\end{tabular}


Table 4 The annual incidence $(/ 100,000)$ of forearm and humeral fractures in women predicted from the epidemiology in Malmo (see methods) and that observed in the present study with $95 \%$ confidence intervals $(\mathrm{CI})$

\begin{tabular}{|c|c|c|c|c|c|c|}
\hline \multirow[t]{2}{*}{ Age (years) } & \multicolumn{3}{|l|}{ Forearm } & \multicolumn{3}{|l|}{ Humerus } \\
\hline & Predicted & Observed & $95 \% \mathrm{CI}$ & Predicted & Observed & $95 \% \mathrm{CI}$ \\
\hline \multicolumn{7}{|l|}{ Men } \\
\hline $50-59$ & 298 & 229 & $162-315$ & 113 & 109 & 64-172 \\
\hline $60-69$ & 286 & 206 & $126-318$ & 103 & 154 & $85-255$ \\
\hline $70-79$ & 85 & 78 & $16-226$ & 128 & 52 & $6-187$ \\
\hline $80-89$ & 79 & 165 & $20-598$ & 100 & 0 & $0-305$ \\
\hline \multicolumn{7}{|l|}{ Women } \\
\hline $50-59$ & 516 & 804 & 689-934 & 148 & 164 & $114-228$ \\
\hline $60-69$ & 497 & 673 & $546-821$ & 188 & 271 & $192-370$ \\
\hline $70-79$ & 640 & 743 & $556-971$ & 332 & 294 & $182-450$ \\
\hline $80-89$ & 507 & 748 & $457-1156$ & 338 & 599 & 342-972 \\
\hline
\end{tabular}

The observations in bold denote a significant difference between observed and predicted estimates

\section{Discussion}

This study documented the incidence of hip, distal forearm and proximal humeral fractures in a region of Kazakhstan. As expected, hip fractures were more frequent in women than in men (female/male ratio $=1.6)$. In both sexes, the incidence increased with age. It is of interest that for individuals younger than 70 years, the hip fracture rate among men was slightly higher than in women. Thereafter, incidence was higher in women. Similar results have been reported in several studies [24, 26-28] including other countries of the EVA project, namely Armenia [10], Belarus [11], Moldova [12] and Russia [9]. Assuming that the regional incidence was similar to the national incidence, Kazakhstan belongs to the moderate-risk countries for hip fracture for men and women [29].

The number of hip fractures nationwide was estimated at 11,690 in 2015.

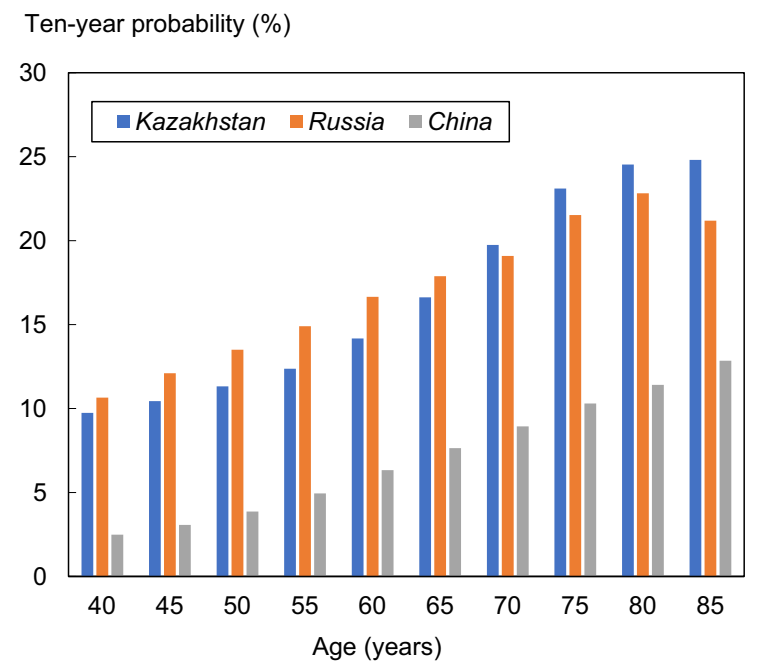

Demographic projections indicate that the annual number of hip fractures will increase by $140 \%$ to 28,048 in 2050 . These estimates are relatively robust in that all individuals who will be aged 60 years, or more in 2050 are currently adults. However, these estimates may be conservative since they assume that the age- and sex-specific risk of hip fracture remains unchanged over this period. If the age- and sex-specific incidence of hip fracture increases, as has been registered in several countries [30], then the number of fractures may be more than doubled. Such projections are important for healthcare planning.

The access to all medical records in this study, including those from primary care, permitted the identification patients with hip fracture who were not admitted to hospital. The reason for this strategy was the observation that many patients in Eastern Europe are not hospitalized because facilities for surgical management are limited so that hospital admission is not feasible. In Belarus, for example, $29 \%$ cases of hip fracture did not come to hospital attention [11]. High rates of non-

Ten-year probability (\%)

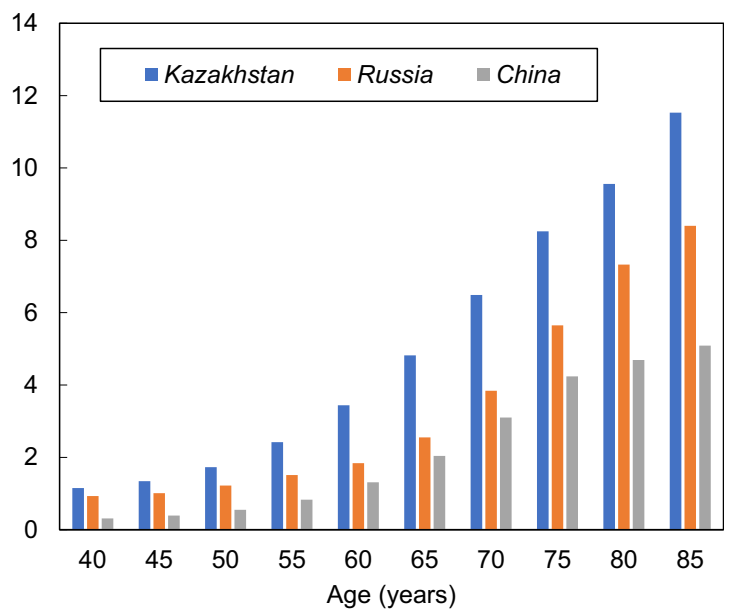

Fig. 1 Ten-year probability of a major osteoporotic fracture (left hand panel) and hip fracture (right) in women with a prior fracture by age from Kazakhstan, Russia and China. Body mass index set to $25 \mathrm{~kg} / \mathrm{m}^{2}$ 
Table 5 Life-time probability of hip fracture in the Kazakh population from the age of 50 years compared with selected countries

\begin{tabular}{|c|c|c|}
\hline \multirow[t]{2}{*}{ Country } & \multicolumn{2}{|c|}{ Life-time risk at 50 years $\%$} \\
\hline & Women & Men \\
\hline Sweden & 25.6 & 11.0 \\
\hline Denmark & 23.0 & 11.3 \\
\hline France & 19.3 & 5.9 \\
\hline China (Hong Kong) & 17.7 & 7.6 \\
\hline USA (Caucasian) & 16.1 & 7.5 \\
\hline Turkey $^{\mathrm{a}}$ & 15.9 & 3.6 \\
\hline Canada & 15.5 & 5.8 \\
\hline Greece & 15.4 & 6.8 \\
\hline UK & 14.4 & 5.0 \\
\hline Portugal & 13.7 & 4.8 \\
\hline Finland & 12.9 & 6.0 \\
\hline Kazakhstan $^{\text {b }}$ & 12.6 & 6.0 \\
\hline Spain & 12.6 & 4.2 \\
\hline Bulgaria & 11.2 & 4.4 \\
\hline Hungary & 10.8 & 4.2 \\
\hline Mexico $^{\mathrm{c}}$ & 10.6 & 5.0 \\
\hline Poland $^{\mathrm{d}}$ & 10.1 & 4.2 \\
\hline Moldova ${ }^{\mathrm{e}}$ & 9.3 & 5.7 \\
\hline Russia $^{f}$ & 7.7 & 3.8 \\
\hline Serbia & 7.6 & 3.7 \\
\hline Romania $^{\mathrm{g}}$ & 7.1 & 3.8 \\
\hline China & 5.9 & 3.3 \\
\hline Ukraine $^{\mathrm{h}}$ & 5.6 & 2.9 \\
\hline
\end{tabular}

abcdefgh From [20] except where indicated; Tuzun et al. 2011 [21]; This study; Clark et al., 2005 [22]; Czerwinski et al., 2009 [23]; Zakroyeva et al. 2019 [12]; Lesnyak et al. 2012 [9]; Grigorie et al. 2013 [24]; Povoroznyuk et al. 2017 [25]

admittance have been reported in Armenia (44\%) [10], Pervouralsk in Russia (27\%) [9], Georgia (75\%) and Kyrgyzstan (50\%) [31]. The present study indicated that $25 \%$ of hip fracture cases were not admitted to hospital, and $43 \%$ of hip fracture cases were either untreated or managed conservatively. The treatment gap arises for many reasons including a lack of emergency orthopaedic surgeons. These findings are important for healthcare planning; they also emphasize the importance of exploring care pathways in the design of epidemiological studies.

A minority of countries that have a FRAX model also have robust information on the risk of other major osteoporotic fractures. In the absence of such information, FRAX models are based on the assumption that the age- and sex-specific pattern of these fractures is similar to that observed in Malmo [16]. This assumption has been shown to be safe in studies reported from Canada [18], Iceland [17], the USA [32], the UK [33], Australia [34] and Moldova [12], despite the differences in incidence between these countries [29]. This commonality of pattern is supported by register studies, which indicate that in those regions where hip fracture rates are high, so too is the risk of forearm fracture and spine fractures (requiring hospital admission) [35-37].

The acquisition of data on the incidence of forearm and humerus fractures as well as for hip fracture permitted the adequacy of this assumption to be tested in the present study, at least for forearm and humeral fractures. Our findings suggest that the incidence of forearm and humerus fractures can be reasonably predicted from the incidence of hip fracture in men. In women, however, the observed fracture rates exceeded those predicted from the Malmo ratios, in some cases significantly so. This disparity may arise because humeral and distal forearm fractures are relatively more common than hip fractures in women from Kazakhstan than in other counties. Unexpectedly, high rates of forearm and humeral fractures have been reported in Russia [9] and Hungary [27]. An alternative explanation is that not all cases of hip fracture were identified, particularly in women. The present study could not address the alternatives.

The incidence of hip fracture was used to create a FRAX tool to compute the 10-year probabilities of hip and major osteoporotic fracture in Kazakhstan. Ten-year probabilities were consistently higher than in the neighbouring country of China but for major osteoporotic fractures similar to that reported for Russia.

The widespread availability of FRAX has resulted in its adoption in many practice guidelines worldwide [7]. The fracture probability equivalent to a woman with a prior fracture has been used as an intervention threshold in more than 30 countries. If the same threshold were applied to Kazakhstan, then intervention would be recommended with a probability of a major fracture that varied between 9.7 and $25 \%$ depending on age (see Fig. 1). The impact of such thresholds or alternative thresholds will require further study.

There are a number of additional limitations to this study. With regard to fracture incidence, we examined only about $1 \%$ of the Kazakh population from a single centre. Therefore, the extrapolation of this regional estimate to the entire country is an assumption that we were unable to test. In addition to large variations in fracture rates around the world, fracture rates may vary within countries. In addition to ethnic-specific differences [38], up to two-fold differences in hip fracture incidence have been reported using common methodology with the higher rates in urban communities including Croatia [39], Switzerland [40], Norway [41], Argentina [42] and Turkey [43]. No distinction was made in the level of trauma. However, the division between high and low trauma is problematic in that osteoporotic patients fracture more commonly than non-osteoporotic patients following high trauma $[44,45]$. Additionally, BMD is similar in patients with hip fracture, irrespective of the level of trauma [46]. These data support the inclusion of high-trauma fractures in epidemiological assessment. 
As noted above, it is possible that not all hip fractures were captured, an effect that would give rise to a systematic underestimate of fracture probabilities for both hip fracture and major osteoporotic fracture. It is relevant, however, that accuracy errors have little impact on the rank order with which the FRAX tool categorizes risk in a given population [10, 25, 47], but they do change the absolute number generated, and thus have implications where treatment guidelines are based on cost-effectiveness or the economic burden of disease.

In summary, a FRAX model has been created for the Republic of Kazakhstan that based on a regional populationbased estimate of the incidence of hip fracture. The model should enhance accuracy of determining fracture probability among the Kazakh population and help to guide decisions about treatment.

Acknowledgements The authors thank Dr. Anarbek Mongol (Chief traumatologist of Almaty Region, Taldykorgan city Hospital), Dr. Toleukhanova L.O., Dr. Shumilova A.G. (Taldykorgan city polyclinic № 1), Dr. Kraisman V.A., Dr. Aikulov K.K. ("Nur-Avicenum” Clinic), Zhanabekova I.G. (Taldykorgan city polyclinic № 2), Kalibekov A.T. (Regional Hospital of Taldykorgan city), Dr. Kanatuly A. ("Hak Medical" Clinic) and Almaty Region Department of Health Care for their administrative assistance in performing of this study. The EVA project was supported by the International Osteoporosis Foundation (Epidemiology and quality of life working group). Servier, however, is acknowledged in helping with organization of the EVA project; 'Epidemiology of osteoporotic fractures in Eurasian counties' study (EVA or ЭBA, in Russian), of which this paper is one of the outcomes.

\section{Compliance with ethical standards}

\section{Conflict of interest None.}

Human and animal rights and informed consent All procedures performed in studies involving human participants were conducted in accordance with the ethical standards of the institutional and national research committee and with the 1964 Helsinki Declaration and its later amendments or compatible ethical standards.

Open Access This article is licensed under a Creative Commons Attribution 4.0 International License, which permits use, sharing, adaptation, distribution and reproduction in any medium or format, as long as you give appropriate credit to the original author(s) and the source, provide a link to the Creative Commons licence, and indicate if changes were made. The images or other third party material in this article are included in the article's Creative Commons licence, unless indicated otherwise in a credit line to the material. If material is not included in the article's Creative Commons licence and your intended use is not permitted by statutory regulation or exceeds the permitted use, you will need to obtain permission directly from the copyright holder. To view a copy of this licence, visit http://creativecommons.org/licenses/by/4.0/.

\section{References}

1. Hernlund E, Svedbom A, Ivergård M, Compston J, Cooper C, Stenmark J, McCloskey EV, Jönsson B, Kanis JA (2013) Osteoporosis in the European Union: medical management, epidemiology and economic burden. A report prepared in collaboration with the international Osteoporosis Foundation (IOF) and the European Federation of Pharmaceutical Industry Associations (EFPIA). Archives of osteoporosis 8:136

2. Johnell O, Kanis JA (2006) An estimate of the worldwide prevalence and disability associated with osteoporotic fractures. Osteoporos Int 17:1726-1733

3. Kanis JA, Cooper C, Rizzoli R, Reginster J-Y, Scientific Advisory Board of the European Society for Clinical and Economic Aspects of Osteoporosis (ESCEO) and the Committees of Scientific Advisors and National Societies of the International Osteoporosis Foundation (IOF) (2019) European guidance for the diagnosis and management of osteoporosis in postmenopausal women. Osteoporos Int 30:3-44

4. Kanis JA On behalf of the World Health Organization scientific group (2008a) assessment of osteoporosis at the primary healthcare level. technical report. WHO collaborating Centre, University of Sheffield, UK. Available at . http://www.shef.ac.uk/FRAX/pdfs/ WHO_Technical_Report.pdf. Accessed 26 Feb 2019

5. Kanis JA, Johnell O, Oden A, Johansson H, McCloskey E (2008a) FRAX $^{\mathrm{TM}}$ and the assessment of fracture probability in men and women from the UK. Osteoporos Int 19:385-397

6. Odén A, McCloskey EV, Kanis JA, Harvey NC, Johansson H (2015) Burden of high fracture probability worldwide: secular increases 2010-2040. Osteoporos Int 26:2243-2248

7. Kanis JA, Harvey NC, Cyrus Cooper C, Johansson H, Odén A, McCloskey EV the Advisory Board of the National Osteoporosis Guideline Group (2016) A systematic review of intervention thresholds based on FRAX. A report prepared for the National Osteoporosis Guideline Group and the International Osteoporosis Foundation. Arch Osteoporos 11:25

8. Kanis JA, Johansson H, Harvey NC, McCloskey EV (2018) A brief history of FRAX. Arch Osteoporos 13:118. https://doi.org/10.1007/ s11657-018-0510-0

9. Lesnyak O, Ershova O, Belova K, Gladkova E, Sinitsina O, Ganert O, Romanova M, Khodirev V, Johansson H, McCloskey E, Kanis JA (2012) Epidemiology of fracture in the Russian Federation and the development of a FRAX model. Arch Osteoporos 7:67-73. https://doi.org/10.1007/s11657-012-0082-3

10. Lesnyak O, Sahakyan S, Zakroyeva A, Bilezikian JP, Hutchings N, Galstyan R, Lebedev A, Johansson H, Harvey NC, McCloskey E, Kanis JA (2017) Epidemiology of fractures in Armenia: development of a country-specific FRAX model and comparison to its surrogate. Arch Osteoporos 12(1):98. https://doi.org/10.1007/ s11657-017-0392-6

11. Ramanau H, Chernyanin I, Rudenka E, Lesnyak O, Zakroyeva A, Bilezikian JP, Johansson H, Harvey NC, McCloskey EV, Kanis JA (2018) Epidemiology of hip fracture in Belarus: development of a country-specific FRAX model and its comparison to neighboring country models. Arch Osteoporos 13:42. https://doi.org/10.1007/ s11657-018-0454-4

12. Zakroyeva A, Lesnyak O, Cazac V, Groppa L, Russu E, Chislari L, Rotaru L, Johansson H, Harvey NC, McCloskey E, Kanis JA (2019) Epidemiology of osteoporotic fracture in Moldova and development of a country specific FRAX model. Arch Osteoporos

13. United Nations (2017) DESA / population division. World Population Prospects 2017 https://population.un.org/wpp/ Download/Standard/Population/. Accessed 15 Feb 2019

14. Committee on Statistics (2016) Ministry of National Economy of the Republic of Kazakhstan. Demography Series 14 and 23 Astana, Kazakhstan http://statgovkz/faces/wcnav_externalId/publBullS142016 ? afrLoop $=454097060173607 \overline{6} \# \% 40 \% 3 \mathrm{~F}$ afrLoop $\%$ 3D4540970601736076\%26 adfctrl-state\%3D2cz2zgqkv_298 [in Kazakh, Russian] Accessed 12 May 2019

15. United Nations (2017) Department of Economic and Social Affairs / population division. World Population Prospects https:// 
wwwworldometersinfo/world-population/kazakhstan-population/ Accessed 12 May 2019

16. Kanis JA, Oden A, Johnell O, Jonsson B, de Laet C, Dawson A (2001) The burden of osteoporotic fractures: a method for setting intervention thresholds. Osteoporos Int 12:417-427

17. Siggeirsdottir K, Aspelund T, Johansson H, Gudmundsson EF, Mogensen B, Jonsson BY, Gudnason V, McCloskey E, Oden A, Sigurdsson G, Kanis JA (2014) The incidence of a first major osteoporotic fracture in Iceland and implications for FRAX. Osteoporos Int 25:2445-2451

18. Lam A, LeslieWD LLM, Yogendran M, Morin SN, Majumdar SR (2014) Major osteoporotic to hip fracture ratios in Canadian men and women with Swedish comparisons: a population-based analysis. J Bone Miner Res 29:1067-1073

19. World Health Organization (2018) Health statistics and information systems: http://www.who.int/healthinfo/statistics/mortality rawdata/en/ Accessed 17 June 2019

20. Kanis JA, Johnell O, De Laet C, Jonsson B, Oden A, Ogelsby AK (2002) International variations in hip fracture probabilities: implications for risk assessment. J Bone Miner Res 17:1237-1244

21. Tuzun S, Eskiyurt N, Akarırmak U, Sarıdoğan M, Senocak M, Johansson H, Kanis JA, the Turkish Osteoporosis Society (2012) Incidence of hip fracture and prevalence of osteoporosis in Turkey: the FRACTURK study. Osteoporos Int 23:949-955

22. Clark P, Lavielle P, Franco-Morina F, Ramirez E, Salmeron J, Kanis JA, Cummings SR (2005) Incidence rates and life-time risk of hip fractures in Mexicans over 50 years of age: a population-based study. Osteoporos Int 16:2025-2030

23. Czerwinski E, Kanis JA, Trybulec B, Johansson H, Borowy P, Osieleniec J (2009) The incidence and risk of hip fracture in Poland. Osteoporos Int 20:1363-1367

24. Grigorie D, Sucaliuc A, Johansson H, Kanis JA, McCloskey E (2013) Incidence of hip fracture in Romania and the development of a Romanian FRAX model. Calcif Tiss Int 92:429-436

25. Povoroznyuk VV, Grygorieva NV, Kanis JA, McCloskey EV, Johansson H, Harvey NC, Korzh MO, Strafun SS, Vaida VM, Klymovytsky FV, Vlasenko RO, Forosenko VS (2017) Epidemiology of hip fracture and the development of FRAX in Ukraine. Arch Osteoporos 12:53

26. Stepan JJ, Vaculik J, Pavelka K, Zofka J, Johansson H, Kanis JA (2012) Hip fracture incidence from 1981 to 2009 in the Czech Republic as a basis of the country-specific FRAX model. Calcif Tissue Int 90:365-372

27. Péntek M, Horváth C, Boncz I, Falusi ZTóth E, Sebestyén A, Májer I, Brodszky V, Gulácsi L (2008) Epidemiology of osteoporosis related fractures in Hungary from the nationwide health insurance database, 1999-2003. Osteoporos Int 19:243-249

28. Dimai HP, Svedbom A, Fahrleitner-Pammer A, Resch H, Muschitz C, Thaler H, Szivak M, Amrein K, Borgström F (2014) Epidemiology of distal forearm fractures in Austria between 1989 and 2010. Osteoporos Int 25:2297-2306

29. Kanis JA, Oden A, McCloskey EV, Johansson HD, Wahl A, Cooper C (2012) A systematic review of hip fracture incidence and probability of fracture worldwide. Osteoporos Int 23(9): 2239-2256

30. Cooper C, Cole ZA, Holroyd CR, Earl SC, Harvey NC, Dennison EM, Melton LJ, Cummings SR, Kanis JA, the IOF CSA Working Group on Fracture Epidemiology (2011) Secular trends in the incidence of hip and other osteoporotic fractures. Osteoporos Int 22: $1277-1288$

31. International Osteoporosis Foundation (2011) The Eastern European \& Central Asian Regional Audit. Epidemiology, costs $\&$ burden of osteoporosis in 2010. Naturaprint, France. Available at https://www.iofbonehealth.org/sites/default/files/PDFs/Audit\%
20Eastern\%20Europe_Central\%20Asia/Eastern_European Central Asian Audit 2010.pdf. Accessed 11 Dec 2018

32. Melton LJ, Crowson CS, O'Fallon WM (1999) Fracture incidence in Olmsted County, Minnesota: comparison of urban and with rural rates and changes in urban rates over time. Osteoporos Int 9:29-37

33. Singer BR, McLauchlan CJ, Robinson CM, Christie J (1998) Epidemiology of fracture in 15.000 adults. The influence of age and gender. J Bone Joint Surg 80B:234-238

34. Sanders KM, Seeman E, Ugoni AM, Pasco JA, Martin TJ, Skoric B, Nicholson GC, Kotowicz MA (1999) Age- and gender specific rate of fractures in Australia: a population-based study. Osteoporos Int 10(2):40-47

35. Kanis JA, Johnell O, Oden A, Sernbo I, Redlund-Johnell I, Dawson A, de Laet C, Jonsson B (2000) Long-term risk of osteoporotic fractures in Malmo. Osteoporos Int 11:669-674

36. Johnell O, Gullberg B, Kanis JA (1997) The hospital burden of vertebral fracture in Europe: a study of national register sources. Osteoporos Int 7:138-144

37. Melton LJ (1995) Epidemiology of fractures. In: Riggs BL, Melton LJ (eds) Osteoporosis: etiology, diagnosis and management, 2ndedn. Lippincott-Raven, Philadelphia, pp 225-227

38. Cauley JA, Chalhoub D, Kassem AM, El-H FG (2014) Geographic and ethnic disparities in osteoporotic fractures. Nat Rev Endocrinol 10:338-351

39. Karacić TP, Kopjar B (2009) Hip fracture incidence in Croatia in patients aged 65 years and more. Lijec Vjesn 131:9-13

40. Lippuner K, Johansson H, Kanis JA, Rizzoli R (2010) FRAX assessment of osteoporotic fracture probability in Switzerland. Osteoporos Int 21:381-389

41. Emaus N, Olsen LR, Ahmed LA, Balteskard L, Jacobsen BK, Magnus T, Ytterstad B (2011) Hip fractures in a city in northern Norway over 15 years: time trends, seasonal variation and mortality: the Harstad injury prevention study. Osteoporos Int 22:26032610

42. Morosano M, Masoni A, Sánchez A (2005) Incidence of hip fractures in the city of Rosario. Argentina: Osteoporos Int 16:13391344

43. Elffors L, Allander E, Kanis JA, Gullberg B, Johnell O, Dequeker J, Dilzen G, Gennari C, Lopez-Vaz AA, Lyritis G, Mazzuoli GF, Miravet L, Passeri M, Perez Cano R, Rapado A, Ribot C (1994) The variable incidence of hip fracture in southern Europe. The MEDOS study. Osteoporos Int 4:253-263

44. Sanders KM, Pasco JA, Ugoni AM, Nicholson GC, Seeman E, Martin TJ, Skoric B, Panahi S, Kotowicz MA (1998) The exclusion of high trauma fractures may underestimate the prevalence of bone fragility fractures in the community: the Geelong osteoporosis study. J Bone Miner Res 13:1337-1342

45. Mackey DC, Lui LY, Cawthon PM, Bauer DC, Nevitt MC, Cauley JA, Hillier TA, Lewis CE, Barrett-Connor E, Cummings SR, Study of Osteoporotic Fractures (SOF) and Osteoporotic Fractures in Men Study (MrOS) Research Groups (2007) High-trauma fractures and low bone mineral density in older women and men. JAMA 298: 2381-2388

46. Leslie WD, Schousboe JT, Morin SN, Martineau P, Lix JM, Johansson H, McCloskey EV, Harvey NC, Kanis JA (2020) Fracture risk following high-trauma versus non-trauma fracture: a registry-based cohort study. Osteoporos Int, in press

47. Kanis JA, Johansson H, Oden A, Dawson-Hughes B, Melton LJ 3rd, McCloskey EV (2010) The effects of a FRAX® revision for the USA. Osteoporos Int 21:35-40

Publisher's note Springer Nature remains neutral with regard to jurisdictional claims in published maps and institutional affiliations. 